\title{
Economic Assessment of Technology Adoption in Oil Palm Plantations from Colombia
}

\author{
Mauricio Mosquera-Montoya ${ }^{1}$, Elizabeth Ruiz-Alvarez ${ }^{1} \&$ Eloina Mesa-Fuquen $^{1}$ \\ ${ }^{1}$ Economic Assessment Research Program, Corporación Centro de Investigación en Palma de Aceite (Cenipalma), \\ Colombia \\ Correspondence: Mauricio Mosquera-Montoya, Economic Assessment Research Program, Corporación Centro de \\ Investigación en Palma de Aceite (Cenipalma), Colombia.
}

Received: May 22, 2017

Accepted: June 16, 2017

Online Published: June 21, 2017

doi:10.5430/ijfr.v8n3p74

URL: https://doi.org/10.5430/ijfr.v8n3p74

\begin{abstract}
Adopting technology regarding agricultural crops has traditionally been associated with high costs. Producers have thus often abstained from adopting better agronomical practices and have consequently lost the benefits they could otherwise have obtained by implementing better criteria for managing their crops.

This research builds on results by Ruiz et al., (2017) who found three typologies of oil palm lots, regarding adoption of technology and yields on oil palm crops from Colombia. This work was aimed at evaluating the typologies found by Ruiz et al. (2017) from an economic standpoint by using different economic assessment methods, in order to determine the benefits of technology adoption at the Colombian oil palm agroindustry. The methods used were aimed at estimating: unit cost, net present value (NPV), net income, land use efficiency, generation of income and competitiveness.

Results indicate that the cost of producing a ton of fresh fruit bunches from oil palms (FFB) on lots having high adoption of technology was $2.5 \%$ to $8 \%$ lower when compared to lots having lower adoption of technology (Typologies 2 and 3. respectively). Technology adoption enables greater yearly net income to be obtained in mature oil palm crops in typology 1 , than the one obtained at typology 2 and typology 3 . The adoption of technology allows the grower to obtain net income equivalent to a legally-established yearly minimum wage (LEYMW), using less land. Finally, it was concluded that at average CPO prices for the period 2005-2015, the Colombian growers that participated in this study, may be competitive at the European market, which is the main destination of Colombian exports of crude palm oil (CPO).
\end{abstract}

Keywords: production costs, index for measuring technology adoption, net present value, net income, competitiveness

\section{Introduction}

The adoption of agronomic techniques by rural producers has been reported as one of the main drivers to reaching high yields in agricultural crops, together with new varieties and management techniques (Fischer, R.A., 2015; Beddow, Hurley \& Pardey, 2014). However, there are obstacles to overcome in order to enhance the adoption of technology. These obstacles may be classified into external obstacles and internal obstacles, depending upon the chances of the producer with regards to handling them. Among external obstacles one may find price fluctuation, trade restrictions, lack of access to financial credit and, the lack of mechanisms to ameliorate the risk, such as crop insurances (Beddow, Harley \& Pardey, 2014).

Previous research has studied the so called "internal obstacles" refraining producers from adopting new technologies. Among them, one finds the socio-economic characteristics of the grower and, the idea that implementing new technologies is expensive. Regarding the former, the results from Ruiz, Mesa, Mosquera, \& Beltrán (2015), indicated that, variables such as poverty, age and, the experience of the grower at cropping oil palms; are related to producers that are reluctant towards adopting new technologies at their oil palm crops. At the contrary, the greater the grade of literacy achieved by the growers, the more prone is the grower to adopt new technologies (Ruiz, Mesa, Mosquera, \& Beltrán, 2015). The latter is also the case, when the grower is attended by an extension service, that points out to him the cost efficiency of investing on novel technologies (Ruiz, Mesa, Mosquera, \& Beltrán, 2015). 
At the Colombian oil palm agroindustry, it is being promoted an institutional arrangement where the companies that buy oil palm fruit from growers, are increasingly in charge of providing technical assistance to their fruit providers and, of facilitating their access to inputs and services (Sanz, Mosquera \& Beltran, 2017). In other words, small scaled oil palm growers from Colombia are being helped to overcome the aforementioned obstacles. The fruit providers benefit from being capable of using the available technology, and consequently, from the greater income coming from greater yields. The company that buys the oil palm fruit benefits from increasing the use of the installed capacity at their mills (Sanz, Mosquera \& Beltran, 2017).

The institutional arrangement just described, relies on the assumption that if growers have access to the necessary financial resources to implement the best technology available for cropping oil palms; they will attain greater yields, which in turn, allows them to obtain greater income. Additionally, producing more with the same amount of natural resources is seen as the right path towards efficient growers.

In Colombia, the relationship between high yields and technology adoption regarding oil palm crops has been well documented. The yield gap in Colombia between producers that have adopted good practices and those who have not adopted them, has been reported as 6.6 t/ha on average (Beltrán, Pulver, Guerrero, \& Mosquera, 2015). Sanz, Mosquera \& Beltrán, (2017) found that adopting good practices could lead to an increased crop yield of up to 13.3 tons of FFB per hectare in a lapse of four years. This implies that agronomic results from using good agricultural practices are evident.

Then, it was necessary to address the question on the cost efficiency of the investment required to implementing good practices. It must be highlighted that the expenses in which the grower incur by unit of area may increase. However, the unit costs may decrease by $16 \%$ (Fontanilla, Mosquera, Ruiz, Beltrán, \& Guerrero, 2015). More important is the fact that, the greater amount of tonnes of FFB that are produced by using good practices, implies that the grower obtains greater net income ranging from USD 292 / ha to USD 984 / ha per year on oil palm plantations (Fontanilla, Mosquera, Ruiz, Beltrán, \& Guerrero, 2015).

However, there are no reports on economic assessment of the use of land in the Colombian oil palm agroindustry. On the other hand, there is also a lack on analysis oriented towards determining the competitiveness of Colombian CPO in external markets, considering that Colombia is a net exporter of crude palm oil. This paper contributes to filling these gaps.

This document summarises economic assessment of the association between technology adoption and, yield gaps; in oil palm crops from Colombia. This work builds on results by Ruiz, Mesa, Mosquera, \& Barrientos, (2017) who, by means of using Multiple Correspondence Analysis (MCA) and Cluster Analysis (CA), found three typologies based on technology adoption and yields, in a sample of providers of FFB from Colombia.

Regarding each typology, production costs were estimated. Additionally, an economic evaluation was made considering two indicators: net present value (NPV) and, yearly net income for oil palms at mature stage (i.e. older than 6 years old). It was also estimated the area of land enabling a producer to earn one legally-established yearly minimum wage (LEYMW). Finally, it was carried out a competitiveness analysis, considering the price of crude palm oil (CPO) that is negotiated at the main export market for the Colombian palm oil (i.e. Rotterdam), and its repercussions in terms of maximum costs at which Colombian growers should produce, given the fact that Colombian growers are price takers at oil palm international markets.

\section{Methodology}

\subsection{Study Region and Objective}

The study was made in the municipalities of Sabana de Torres, Rio Negro, Tamalameque and Rio de Oro. Growers that participated in this study are suppliers of FFB from a company that runs their own crops of oil palm, owns a mill and provides technical assistance to its fruit suppliers, this type of companies are known as nucleus (Note 1) in the Colombian oil palm agroindustry. In total, the nucleus that was studied had 81 FFB suppliers in 2015 (288 lots). Participant fruit suppliers were classified as small- and medium-sized producers (from 20 to $500 \mathrm{ha}$ ).

\subsection{Prior Information}

Ruiz et al., 2017 measured technology adoption on a sample of oil palm lots (33 lots out of 288) belonging to fruit suppliers from a nucleus. The index for measuring technology adoption (IMAT) was used for categorizing the technology adoption of the lots in the sample. The IMAT is an index developed by Cenipalma, it enables to measure the adoption of technology, concerning five main processes involved in cropping oil palms (Franco, Arias, \& Beltran, 2014). 
The IMAT gathers information on 25 practices that are grouped into five crop managing tasks for oil palm (they are plantation establishment, crop nutrition, pests' control, harvest and, weed control). Each practice gets a score given by an oil palm crop expert. There are three possible categories for each practice: fully adopted, partially adopted and, no adopted at all. The IMAT assigns different weights to each practice, depending upon their contribution to yield. The IMAT results from the ratio between the summation of scores obtained for each practice, with respect to the maximum score attainable for all practices, which is 100. In consequence, if there is fully adoption of all recommended practices, the lot is said to have an IMAT of $100 \%$.

Table 1. Lot typology regarding economic analysis

\begin{tabular}{llcc}
\hline \multicolumn{1}{c}{ Lot typology } & $\begin{array}{c}\text { Yield } \\
(\mathbf{t} / \mathbf{h a})\end{array}$ & $\begin{array}{c}\text { (IMAT) } \\
(\boldsymbol{\%})\end{array}$ \\
\hline 1. & High yield - Good IMAT* & 33 & $>80$ \\
2. & Intermediate yield - Acceptable IMAT & $*$ & 60 \\
3. & Low yield - Poor IMAT* & 24 & 40 \\
\hline
\end{tabular}

IMAT: Technology balance index. Typologies were described by Ruiz et al., 2017 (in press).

* IMAT was quantified using Franco et al., (2014), guidelines

Regarding the multivariate statistical methods, Ruiz et al., (2017) used three categories for each practice (i.e. fully adopted, partially adopted and no adoption), in the sampled lots (i.e. 33). The multivariate methods used for finding typologies of lots were multiple correspondence analysis (MCA) and conglomerate analysis (CA). Three lot typologies were identified: lots having yields greater than $30 \mathrm{t} \mathrm{FFB} \mathrm{/} \mathrm{ha} \mathrm{and} \mathrm{IMAT} \mathrm{greater} \mathrm{than} 80 \%$ (typology 1); lots having yields of $24 \mathrm{t}$ FFB /ha and 60\% IMAT (typology 2) and, lots having average yields of $21 \mathrm{t}$ FFB / ha yield and 40\% IMAT (Table 1). This document describes the different approaches to economic assessment of the adoption of technologies, taking as its starting point the three lot typologies found by Ruiz et al. (2017 - In press).

\subsection{Estimation of Production Costs}

A questionnaire based on the Manual for recording costs on small- and medium-sized scale oil palm growers' plantations (Mosquera, Ruiz, Fontanilla, Beltrán \& Arias, 2014) was used for capturing the data. Unit costs were estimated for each lot typology by considering the practices being adopted, their frequency and prices. For cost estimation there were considered the different stages of the oil palm crop lifecycle, these are: establishment (year 0), unproductive stage ( 1 to 3 years), development stage (4 to 6 years) and maturity ( 7 to 30 years).

Variable and fixed costs associated with the production of oil palm fruit were estimated. Variable costs were those related to operational costs associated with production (labour and consumables) regarding the following activities: fertilisation, weed control, pruning, control of pests, maintenance of plantation infrastructure, harvest of FFB and transportation of FFB to the mill. Fixed costs involved the opportunity cost of land and, crop administration.

The same opportunity cost regarding land was considered for the three typologies as the lots were in the same region and $7 \%$ above total costs was considered as administration value. The administration value of $7 \%$ has been estimated for small and medium-scale producers (Fontanilla et al., 2015).

The unit cost (COP/ t FFB) was estimated by adding the costs per hectare incurred by a plantation since its establishment and assuming a 30-year lifecycle for the crop. The yield per hectare during the lifecycle of the crop was also estimated. The technical assistants from the nucleus were asked to reconstruct the curve of yields for each typology during development stage and it was assumed that yields reach its maximum at year 7 and that yields remains stable from year 7 to year 30. Equation 1 (Eq. 1) shows how the unit cost was estimated for each typology. Note, the subindex " $\mathrm{i}$ " refers to the age of the oil palms and " $\mathrm{T}$ " is the final period, when re-planting should take place.

$$
\text { Unit Cost }=\frac{\sum_{i=0}^{T=30}(\text { total cost per } h a)_{i}}{\sum_{i=0}^{T=30}(\text { tons of FFB per ha })_{i}}
$$


For costs estimation, we used prices of 2015. The costs were converted from Colombian pesos (COP) to US-dollars (USD) using 2015 exchange rate (i.e. COP 2,743/1 USD).

\subsection{Economic Assessment}

Profitability indicators were estimated for each typology of producer by projecting a 30-year cash flow, with a discount rate of $8 \%$; which is the real discount rate used by Colombian investors when entering the oil palm cropping business. The cash flow represents income and costs per hectare, estimated for each typology at each period (i.e. year). The profitability indicators considered were net present value (NPV) and annual net income per hectare for mature crops (i.e. crops of oil palm that were older than 6 years in 2015). NPV enables ascertaining the economic viability of establishing oil palm, considering the three typologies studied here; while the annual net income per hectare of mature oil palms, provides an idea of the expected revenue.

The annual net income per hectare of mature oil palms was calculated from the difference between gross income per hectare and the production costs per hectare, (note, both consider oil palms older than 6 years). The former is given by, the yearly amount of tons of FFB that are produced at a hectare planted with oil palms, valued at the average price of a ton of FFB in 2015.

The information on prices was taken from the historical series of current prices paid in Colombia per ton of crude palm oil (Sistema de Información Estadística Palmera [SISPA], 2016), for the period January 2005 to December 2015. This series was converted into real prices by using the series of Consumer Price Index for the same period in Colombia (Departamento Administrativo Nacional de Estadística [DANE], 2016). The real monthly price series was multiplied by $17 \%$ in order to obtain the FFB price series. Note that one needs about five tons of FFB in order to extract a ton of CPO. To the resulting series we calculated average price and the standard deviation. As mentioned before, the resulting values were converted from COP into USD, by using the 2015 yearly average exchange rate (COP 2.743 / 1 US-dollar).Three price scenarios were proposed: average (USD 130 / t FFB), average minus one standard deviation (USD 110 / t FFB) and, average plus one standard deviation (USD 150/ t FFB).

\subsection{Generation of Income}

In Colombia, a legally-established yearly minimum wage (LEYMW) for 2015 was equivalent to USD 4,452 per year, which included $58 \%$ for state-defined obligatory payments (such as health scheme, pension, among others). An attempt was made to ascertain how many hectares are required to provide the equivalent to one LEYMW (i.e. USD 4,452 per year). The amount of land required was calculated for the three typologies.

In order to estimate the land required for providing a grower to obtain USD 4,452 (i.e. the yearly amount of income that is equivalent to earn one LEYMW), it was used the yearly net income per hectare at mature palms (gross income minus production costs). We used the ratio between the yearly net income per hectare divided by the LEYMW (i.e. USD 4,452).

According to the Instituto Colombiano de Desarrollo Rural [INCODER], (2012), a Colombian rural household that obtains less than two LEYMW is considered poor, in terms of income. By considering the average size of plantation for small and medium scale growers (i.e.25 ha); it was determined the amount of LEYMW obtained in 2015, once they covered expenses related to the crop.

\subsection{Competitiveness Analysis for Crude Palm Oil (CPO)}

An analysis was made for determining whether producers from each typology could be competitive in international markets by using the approach by Manjarrez \& Mosquera (2005).

According to Manjarrez \& Mosquera (2005), CPO prices at international markets must be compared to the production costs for each typology in order to determine if a grower can produce at costs that are lower than CPO price. In this sense, the purchase price of oil palm in external markets becomes the reference price that allows Colombian growers to know what should be their maximum production cost, in order to be able of selling abroad.

This analysis considered the average cost, insurance and freight price (CIF price) over the period 2005 to 2015 at Rotterdam, the main destination market of the Colombian CPO. According to FEDEPALMA (2016), 48\% of 438,106 tons of palm oil exported during 2015 was destined to European countries. 


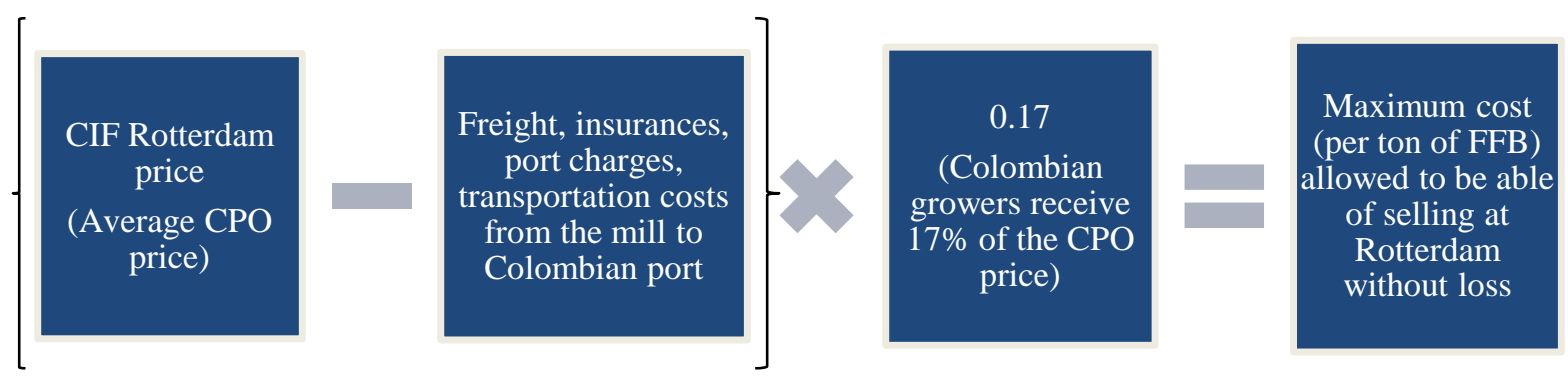

Figure 1. Competitiveness analysis methodology

The goal was to estimate the ceiling of costs so, one must subtract from the CPO CIF price at Rotterdam, the costs in which traders incur to carry the Colombian CPO from Colombia to Europe. These costs are related to freight, insurance, port charges and internal transportation from the mill to the Colombian port (Figure 1). The resulting value should be the maximum CPO cost at the mill (in Colombia), if a Colombian entrepreneur is willing to sell at Rotterdam. In order to convert the CPO maximum costs into FFB maximum unit cost, we used the fact that, on average, the Colombian growers receive $17 \%$ of the CPO price per a ton of FFB.

Note that, if growers are capable to meet this goal of costs, or even, to produce at a lower cost; they will not incur in economic loss if they were to sell their FFB to mills that are extracting CPO to be sold at Europe.

\section{Results and Discussion}

\subsection{Production Costs}

\subsubsection{Outlay (Investment) or Establishing Oil Palms (USD/ha)}

The oil palms must first be established which involves planting-related tasks. Figure 2 shows costs of establishment, regarding the three typologies of lots studied here. The greatest establishment cost (USD 2,312 per ha) was estimated for lots having typology 1 in which a higher level of technology was adopted compared to USD 1,908/ha for lots having typology 2 and, USD 1,902 /ha for lots having typology 3 (Figure 2).

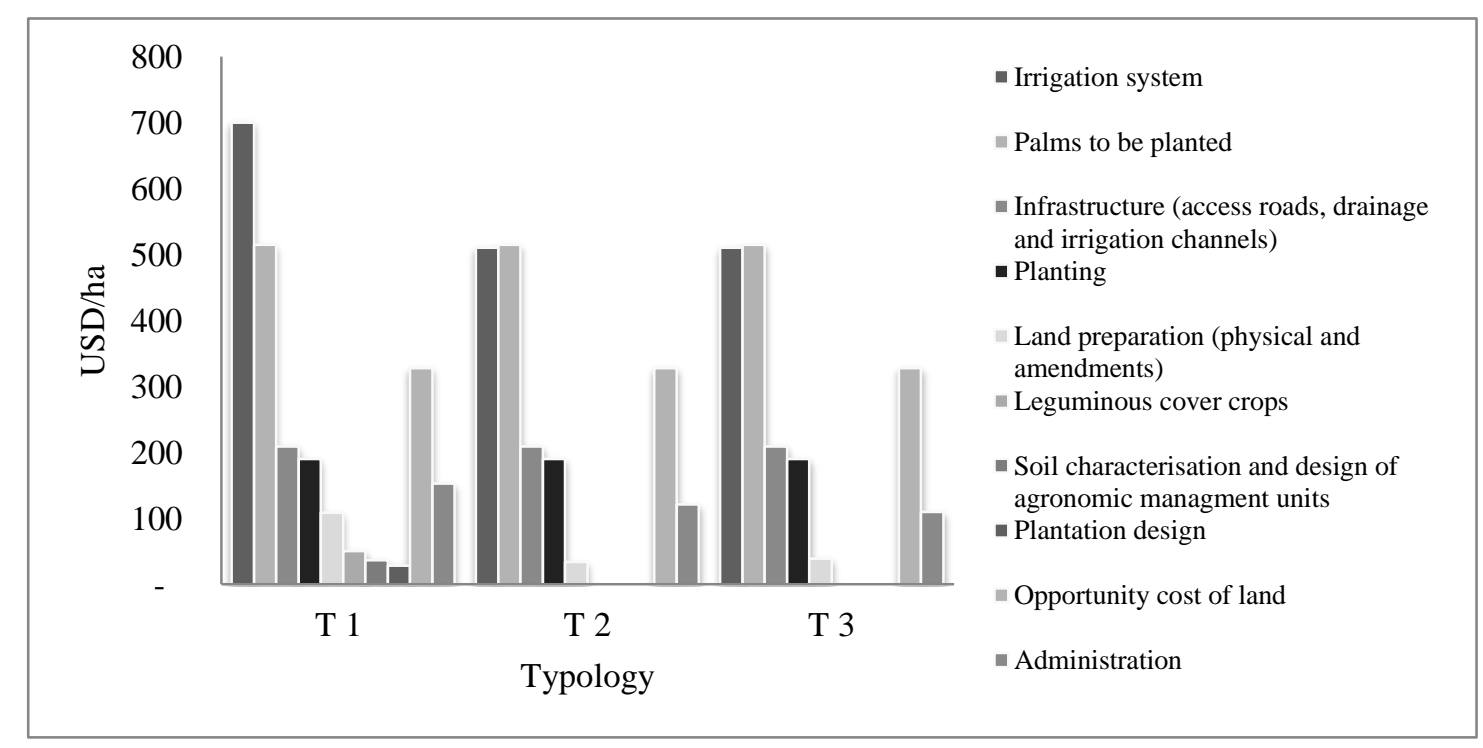

Figure 2. Costs of establishing oil palms by producer typology 
There were differences regarding establishment cost for lots in typology 1, compared to the other two typologies. Lots in typology 1 included the use of altimetry, topography and hydraulic studies, as well as planning infrastructure (i.e. irrigation, drainage and roads) and, soil preparation according to physical and chemical characteristics of soils (Figure 2). Additionally, agronomic management units were delimited regarding soil type similarity, moisture content and planting material. (Figure 2).

\subsubsection{Costs Regarding Non-productive Stage and Development Stage (USD /ha/year)}

During the crop's first three years, there is no production of FFB but the grower must take care of the crop (i.e. non-productive stage). Annual expenses of around USD 1,275 / ha have been estimated for lots having typology 1 during this stage, USD 1,039 / ha for lots having typology 2 and, USD 902 / ha for lots having typology 3.

At the development stage (4-6 years), the annual production costs were estimated at USD 2,176 / ha on lots grouped in typology 1, USD 1,719 / ha on lots having typology 2 and, USD 1,522 / ha for lots having typology 3.

It is evident that the expenses on lots having higher IMAT (typology 1) are greater than those with lower IMAT due to having to carry out tasks which involve greater frequencies and the use of greater amounts of consumables, such as fertilisers. However, deficient crop management during this stage could cause problems in the future. The grower must ensure that palms grow healthy and strong, in order to be productive in the long run and less prone to pests attacks.

\subsubsection{Yearly Costs at Adult Stage (USD /ha/year)}

Adult stage-related annual costs were estimated USD 2,281 / ha on lots having typology 1, USD 1,841 / ha on lots having typology 2 and USD 1,616 / ha on lots having typology 3 (Figure 3). Costs during this stage would thus be 19.2\%-29.2\% greater for lots having higher technology adoption indices regarding typologies adopting less technology.

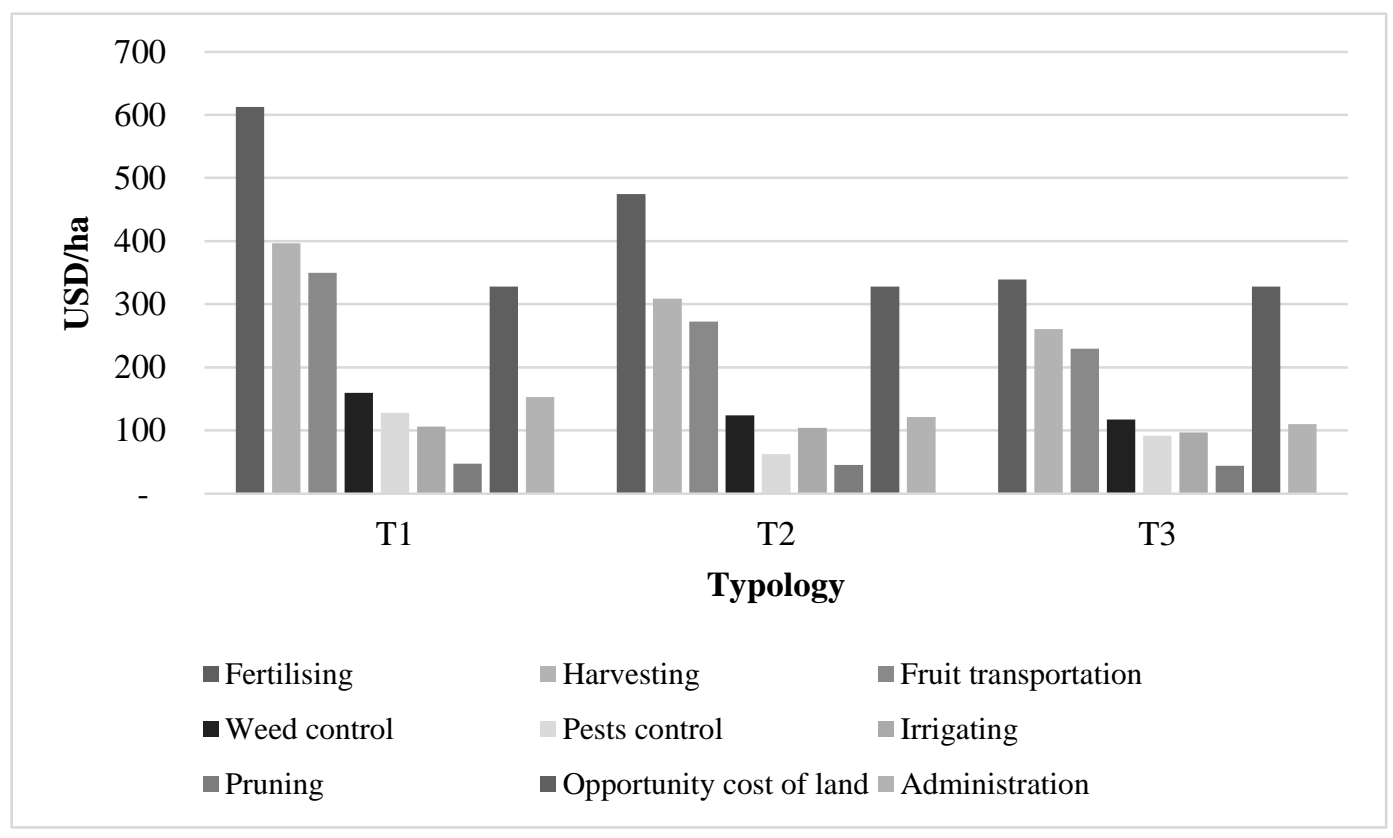

Figure 3. Costs regarding crop management at adult stage

Fertilising was the task accounting for the greatest share of production costs in all typologies (i.e. $21 \%-27 \%$ total cost). The highest cost for typology 1 was due to applying greater amounts of fertiliser. This is worth stressing because, according to Ruiz et al., 2017 (in press), typologies having low technology adoption indices (2 and 3) were only applying 50\%-60\% of the amount of fertiliser demanded by the crop. Consequently, extension efforts should be aimed at encouraging the proper use of this consumable, as in other studies of yield gaps regarding oil palm crops it has been shown to be a factor limiting high yields being obtained (Euler, Hoffmann, Fathoni, \& Schwarze, 2016). 
Other tasks accounting for around 30\% of annual crop maintenance costs in the three typologies were fruit harvesting and transport (Figure 3), these were directly influenced by the amount of fruit produced on a hectare, since payments are set by the ton of FFB (either harvested, or transported).

It was found that harvesting cycles on lots having typology 1 were 10 - 12 days' frequency, this being more extended on lots having lower adoption indices. This is important since harvesting bunches at the right ripeness moment, contributes to avoiding fruits loose on the ground, which happens when fruit bunches are over-ripen (Mosquera \& Fontanilla, 2006). In fact, at some point it will be needed to hire more labour in order to pick up loose fruits; let alone the fact that not every loose fruit is collected.

Other tasks such as weed management and the operation of irrigation systems had different costs depending on typologies, mainly due to the frequency of the tasks carried out during the year, these being higher on lots having typology 1.

3.1.4 Cost per Ton of Fruit Produced (USD / t FFB)

Table 2. Indicators of costs per producer typology

\begin{tabular}{lccc}
\hline \multicolumn{1}{c}{ Indicator } & High & Intermediate & Low \\
\hline Amount of tons of FFB produced in 30 years $(t)$ & 844 & 657 & 552 \\
Long-term cost (USD / $\mathbf{t}$ FFB) & 80 & 82 & 87 \\
\hline
\end{tabular}

The unit cost was estimated considering costs per hectare and the amounts of FFB produced per hectare, regarding each typology considered. Table 2 shows the unit cost for each typology. Contrary to cost per hectare, a lower cost per ton of fruit (FFB) was found in the typology having the higher technology adoption indices (T1). The cost estimated for typology 1 was $2.4 \%$ lower than the cost for typology 2 and $8 \%$ lower for typology 3 having the lowest IMAT (Table 2). In synthesis, technology adoption in oil palm crops leads to greater expenses per hectare. However, it also leads to lower cost per ton of FFB (Table 2).

\subsection{Economic Assessment}

The economic evaluation was aimed at ascertaining the viability of the business by means of two indicators: the NPV and yearly average net income per hectare at mature oil palms. Figure 4 shows the net income flows that were used for estimating NPV and yearly net income (at mature crops) regarding each typology studied; considering average price (i.e. USD 130 / t FFB) (Table 3).

Table 3. Economic viability indicators regarding three price scenarios

\begin{tabular}{cccc}
\hline Price & Typology $\mathbf{1}$ & Typology 2 & Typology 3 \\
\hline & \multicolumn{3}{c}{ Net Present Value } \\
USD 110 / t FFB $^{\mathbf{1}}$ & 3,949 & 1,733 & 967 \\
USD 130 / $^{2}$ FFB $^{2}$ & 8,774 & 5,359 & 4,425 \\
USD 150 $^{\mathbf{t}}$ FFB $^{\mathbf{3}}$ & 13,600 & 8,986 & 7,227
\end{tabular}

\begin{tabular}{|c|c|c|c|}
\hline USD $110 /$ t FFB $^{1}$ & 990 & 672 & 483 \\
\hline USD 130 / t FFB ${ }^{2}$ & 1,650 & 1,152 & 903 \\
\hline USD $150 /$ t FFB $^{3}$ & 2,310 & 1,632 & 1,323 \\
\hline
\end{tabular}

${ }^{1}$ Average real price for the period 2006 to 2015, minus one standard deviation

${ }^{2}$ Average real price for the period 2006 to 2015

${ }^{3}$ Average real price for the period 2006 to 2015 , plus one standard deviation 


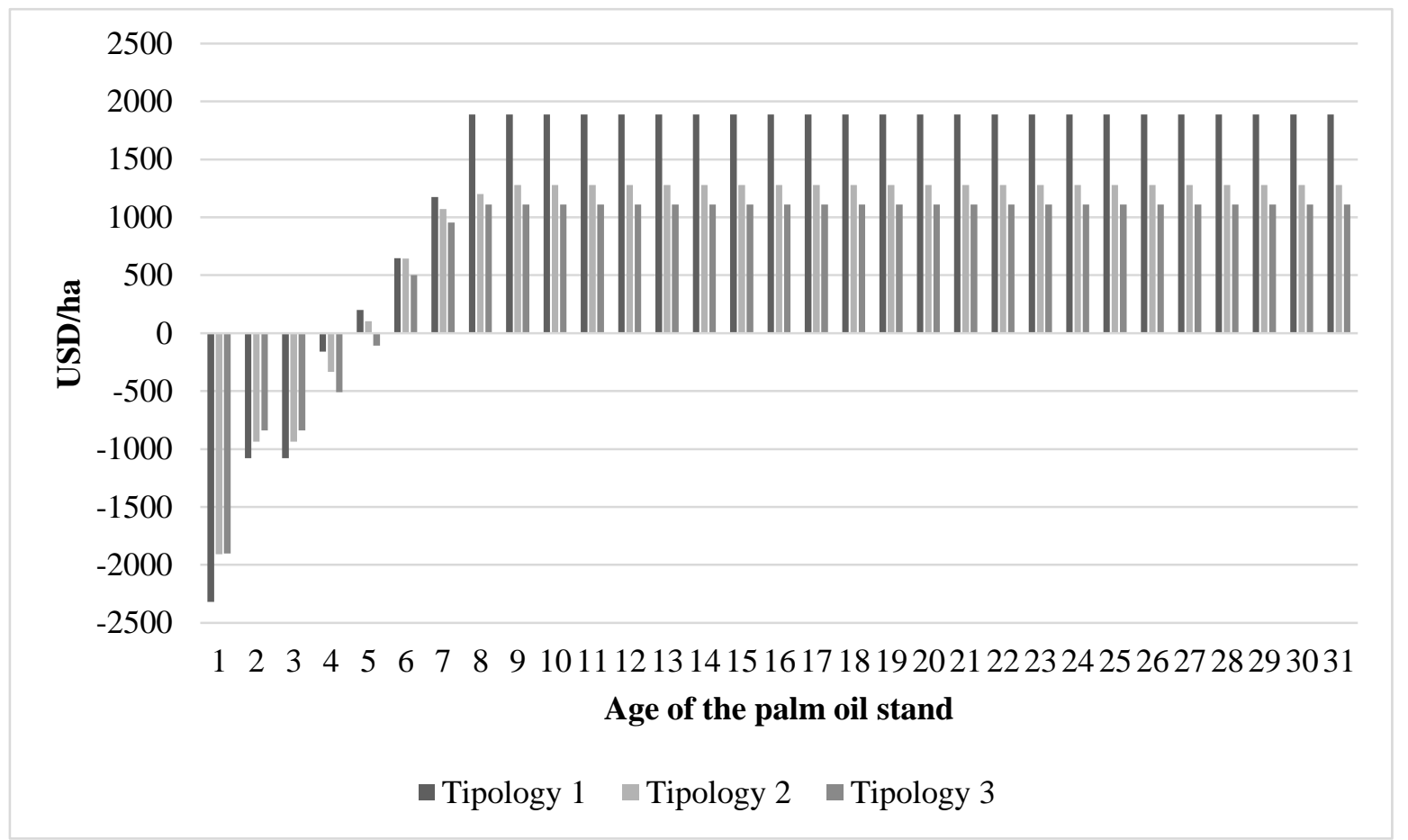

Figure 4. Net income flow regarding the three typologies

The net income flows were negative during the first three years (non-productive stage); however, they became positive in the fourth year regarding typologies 1 and 2, whilst the flow became positive in the fifth year for typology 3 (less technology adoption). Technology adoption regarding establishment and during the first stages of crop development thus favoured the production of greater yield at an earlier stage and therefore enabled producers to have income earlier on. Likewise, their income throughout the life of the project would be greater (Figure 4).

It was found that NPV was positive for lots typologies under study and, at the price scenarios considered, thereby indicating a viable business in all cases. Regarding yearly net income per hectare (in adult palms) it was estimated that it would be $43 \%$ higher on lots having typology 1 compared to typology 2 and, $83 \%$ higher compared to lots having typology 3 (Table 3 ).

Concluding, for lots in the three typologies studied, oil palm has represented an economically viable business, even if yields are of $21 \mathrm{t} \mathrm{FFB} \mathrm{/} \mathrm{ha;} \mathrm{however,} \mathrm{adopting} \mathrm{technology} \mathrm{could} \mathrm{lead} \mathrm{to} \mathrm{increasing} \mathrm{the} \mathrm{amount} \mathrm{of} \mathrm{fruit} \mathrm{and,}$ consequently, the net income received by producers.

\subsubsection{Income Generation}

A larger area was necessary on lots having lower IMAT, in order to obtain a LEYMW, compared to those having higher IMAT. The land area was thus 2.7 ha for typology 1, whilst the land area required was 4.9 ha for typology 3 , featured by lower yields (Table 4).

Since 2004, cropping oil palms has increasingly became an alternative for small holders in Colombia, given the initiative of Productive Alliances that was led by the Colombian Government. Thus, we estimated the amount of LEYMW that could have been produced at a small oil palm plantation with 25 hectares in 2015, according to technology adoption. 25 hectares is the average of land area owned by smallholders that provide FFB to the company that owns the mill. Smallholders represent $70 \%$ of the total number of FFB suppliers. 
Table 4. Area necessary for producing one LEYMW according to yield typologies

\begin{tabular}{lcccccc}
\hline \multicolumn{1}{c}{ Price Scenario } & \multicolumn{3}{c}{ 130 USD/ t FFB } & \multicolumn{3}{c}{ 110 USD/t FFB } \\
\hline \multicolumn{1}{c}{ Typology } & T1 & T2 & T3 & T1 & T2 & T3 \\
Area necessary for a LEYMW* (ha) & 2.7 & 3.9 & 4.9 & 4.5 & 6.6 & 9.2 \\
LEYMW** & 9.3 & 6.5 & 5.1 & 5.6 & 3.8 & 2.7 \\
\hline
\end{tabular}

*Legally established yearly minimum wage, which includes social mandatory payments

** Estimated considering a small holder owning a plantation of 25 ha of oil palms

Results indicate that a producer in typology 1 would have obtained net income equivalent to 9.3 LEYMW, whilst a grower in typology 3 would have obtained net income equivalent to 5.1 LEYMW (Table 4), assuming average price (i.e. USD 130/t FFB). This is a very promising result if one considers that a Colombian rural household is considered poor if it makes less that two LEYMW (INCODER, 2012). The latter indicates that oil palm crops are an alternative to achieve rural development in Colombia, thereby allowing oil palm growers to have a better living standard and to use arable land in a more efficient manner. Note, a grower in typology 1 requires $45 \%$ less land area than a grower in typology 3, to produce one LEYMW (Table 4).

An analysis of sensitivity, considering the lowest price (i.e. USD 110/t FFB) has shown that a greater area would be needed for producing a LEYMW. In this case, 4.5 ha would be required for typology 1 lots in order to produce one LEYMW, obtaining 5.6 LEYMW. On the other hand, 9.2 ha would be required to produce one LEYMW in a scenario involving the lowest technology (i.e. typology 3), and the net income obtained would have been equivalent to 2.7 LEYMW) (Table 4).

\subsubsection{Competitiveness of the CPO Produced by Participating Growers}

The internal palm oil market in Colombia has not grown as expected. In fact, the demands of CPO from Colombian industries, such as the biodiesel and the edible fats, are growing at a slower rate that the amount of CPO produced in Colombia. The mere effect of aging from the currently planted oil palm crops will increase the Colombian CPO production from 1.2 to 2 million tons, during the next five years. The latter, implies that increasing amounts of Colombian CPO must be sold abroad so, it is mandatory for the agroindustry to become competitive at international markets. Thus, it was necessary to determine the ceiling of costs at which Colombian growers should produce to be competitive.

Table 5. Information used in the analysis

\begin{tabular}{lc}
\hline \multicolumn{1}{c}{ Item } & Value \\
\hline CIF price Rotterdam (USD/t CPO) & 785 \\
Freight $^{1}$ (USD/t CPO) & 99 \\
Insurance (USD/t CPO) & 4 \\
Port charges (USD/t CPO) & 10 \\
Transportation from mill to port (USD/t CPO) & 16 \\
CPO ceiling costs (COP/t CPO) & 656 \\
FFB Ceiling costs (COP / t FFB) & 111,5 \\
\hline
\end{tabular}

${ }^{1}$ From Barranquilla (Colombia) to Rotterdam (The Netherlands). COP: Colombian pesos; USD: US-dollars; CPO: crude palm oil; FFB: fresh fruit bunches. Source: Fedepalma

Results show that at a CPO price of USD 785 per ton (average for the period 2005-2015), it would be necessary to produce at a cost of USD 656/ton CPO al mills located at the region where the study was carried out. The latter means that one ton of FFB should cost at the maximum USD 111.5 (Table 5). This ceiling cost was compared to the estimated production costs for each typology considered in this study (Table 6). 
Table 6. Palm oil as exportable product per yield typology at 2015 prices

\begin{tabular}{lccc}
\multicolumn{1}{c}{ Producer typology } & T1 & T2 & T3 \\
\hline Average yield (t/ha) & 33 & 24 & 21 \\
Unit production cost (USD / t FFB) & 80 & 82 & 87 \\
Ceiling costs Average 2005-2015 & (USD/t FFB) & 111.6 & \\
S1. Ceiling costs $\quad$ (USD/t FFB) & 92.8 & \\
S2. Ceiling costs $\quad$ (USD/t FFB) & 84.9 & \\
\hline
\end{tabular}

\section{S1: CPO price at scenario $707 \mathrm{USD} / \mathrm{CPO}$; 2 : CPO price at scenario $628 \mathrm{USD} / \mathrm{t}$ CPO}

To have a better grasp on the long run competitiveness of the studied growers, we also considered two additional price scenarios. We considered decreases of 10\% (USD 707/t CPO) and 20\% (USD 628/t CPO) in the CPO Price. It was found that all producers that participated in this study could compete on the international market if CPO prices are greater than USD 707 / t CPO. However, if prices decrease up to USD 628 / t CPO, the lots in typology 3 would not be able of selling at the international market. This result indicates that adopting technology helps growers to protect themselves from price fluctuation.

\section{Conclusions}

Oil palm is a long-term crop, meaning that decisions taken about its management must be taken accordingly. Crop establishment must thus incorporate available technology; greater investment would thus initially be required in crops having high yields as previous studies have indicated the state of the soil allows suitable plantation design as well as carrying out infrastructure-related work (irrigation, drainage, access roads and crop preparation).

Technology adoption was associated with obtaining high yields on the lots of the suppliers studied here. It was found that the cost of managing a hectare using available technology raised costs by $20 \%$ to $30 \%$ per hectare; however, the amount of fruit obtained on one hectare enabled reducing the cost of producing a ton of fruit by $2.5 \%$ to $8 \%$. This reaffirms the fact that technology adoption contributes towards closing yield gaps and becomes a means of making economic resources used regarding oil palm crops efficient.

The yearly net income at mature crops where technology had been adopted (yields greater than 33 t/ha FFB), exceeded the one received at crops managed with less technology adoption by $43 \%$ to $83 \%$. Thus, even though technology adoption represents greater initial investment and greater cost per hectare, it represents a more profitable business.

It was found that a LEYMW can be produced on 2.7 ha if crops have IMAT of $80 \%$. If there are yield gaps and lower levels of technology adoption, then to obtain a LEYMW takes almost double of land (i.e. 4.9 ha). Finally, if one considers the lowest price and low IMAT, it would be necessary to use 9.2 ha of land to provide the grower with a LEYMW.

The analysis aimed at identifying whether the production costs allow the growers in this sample to compete in international scenarios found that, all producers could compete abroad at a CPO price of USD 707 / t CPO, or higher. Nonetheless, if the CPO price was USD 628 / t CPO, then the lots in typology 3 would not be able of selling at the international market. It allows us to conclude that the adoption of technology, and having higher yields; allows the grower to stay in business, when facing low prices (i.e. CPO price).

This paper contributes to the literature on adoption of technology by providing different approaches to economic assessment which are complementary to each other, and highlights the importance of considering not only cost effectiveness but also, to include in economic analyses topics such as the efficiency on the use of scarce resources and measures of competitiveness.

\section{References}

Beddow, J., Hurley, T., \& Pardey, P. (2014). Food security: Yield Gap. Encyclopedia of Agriculture and Food Systems, 3, 325-365. https://doi.org/10.1016/B978-0-444-52512-3.00037-1 
Beltrán, J., Pulver, E., Guerrero, J., \& Mosquera, M. (2015). Cerrando brechas de productividad con la estrategia de transferencia de tecnología de productor a productor. Palmas, 36(2), 39-54. Retrieved from https://publicaciones.fedepalma.org/index.php/palmas/article/view/11076/pdf_27

DANE. (2016). Indices de Precios al Consumidor. Colombia. Retrieved from https://www.dane.gov.co/index.php/estadisticas-por-tema/precios-y-costos/indice-de-precios-al-consumidor-ipc

Euler, M., Hoffmann, M., Fathoni, Z., \& Schwarze, S. (2016). Exploring yield gaps in smallholder oil palm production systems in eastern Sumatra, Indonesia. Agricultural Systems, 146, 111-119. https://doi.org/10.1016/j.agsy.2016.11.005

Fedepalma. (2016). Anuario Estadístico. La Agroindustria de la Palma de Aceite en Colombia y en el Mundo. Bogotá. Colombia. Ed. Fedepalma

Fischer, R. A. (2015). Definitions and determination of crop yield, yield gaps, and of rates of change. Field Crops Research, 182, 9-18. http://doi.org/http://dx.doi.org/10.1016/j.fcr.2014.12.006

Fontanilla, C., Mosquera, M., Ruiz, E., Beltrán, J., \& Guerrero, J. (2015). Beneficio económico de la implementación de buenas prácticas en cultivos de palma de aceite de productores de pequeña escala en Colombia. Revista Palmas, 27-38. Retrieved from https://publicaciones.fedepalma.org/index.php/palmas/article/view/11075

Franco, P., Arias, N., \& Beltrán, J. (2014). Calificación del nivel tecnológico de las plantaciones de palma de aceite en Colombia. Bogotá, Colombia.

INCODER. (2012). Qué es una Unidad Agrícola Familiar (UAF)? Retrieved from http://www.incoder.gov.co/contenido/contenido.aspx?conID=1663\&catID=1

Manjarrez \& Mosquera. (2005). Diagnóstico económico de las alianzas productivas. Cenipalma - Fedepalma. Informe al Ministerio de Agricultura y Desarrollo Rural.

Mosquera, M., \& Fontanilla, C. (2006). Evaluación de dos metodologías para el proceso de cosecha en palma de aceite. Revista Palmas, 27(1), 4-11. Retrieved from https://publicaciones.fedepalma.org/index.php/palmas/article/view/1168

Mosquera, M., Ruiz, E., Fontanilla, C., Beltrán, J., \& Arias, N. (2014). Manual para el registro de costos en plantaciones de palmicultores de pequeña y mediana escala. Fedepalma. Bogotá - Colombia.

Ruiz, E., Mesa, E., Mosquera, M., \& Barrientos, J. (2017). Technological factors associated with Oil Palm Yield Gaps at Sur Cesar Colombia. Acta Agronómica. In Press.

Ruiz, E., Mesa, E., Mosquera, M., \& Beltrán, J. (2015). Ubicación de hojas cortadas durante la poda y la cosecha alrededor de las palmas como mulch: estudio de adopción de la práctica en cultivadores de palma de aceite en Tibú. Revista Palmas, 36(3), 11-23. Retrieved from https://publicaciones.fedepalma.org/index.php/palmas/article/view/11573

Sanz, J., Mosquera, M., \& Beltrán, J. Narrowing The Yield Gap In Colombia: Water Deficit Mitigation In Crops From Small And Medium Scale Oil Palm. Chapter 17. In: Achieving sustainable cultivation of oil palm Volume 2. Editor Alain Rival. Montpellier, France.

SISPA. (2016). Sistema de Información Estadística Palmera. Precios Nacionales de los productos de la Palma de Aceite. Fedepalma. Retrieved from http://sispaweb.fedepalma.org/login.aspx

\section{Note}

Note 1. An oil palm growing nucleus refers to a scheme in which Colombian oil palm producers constitute a cluster including oil palm growers who sell fruit to a processing plant, all located geographically close to each other. 